\title{
A EFETIVIDADE DA COMPENSAÇÃO AMBIENTAL COMO CONDICIONANTE NO PROCESSO DE LICENCIAMENTO AMBIENTAL
}

\section{THE COMPENSATION OF EFFECTIVENESS ENVIRONMENTAL AS A CONDITION IN THE PROCESS OF ENVIRONMENTAL LICENSING}

\author{
${ }^{1}$ Monike Valent Silva Borges \\ ${ }^{2}$ Verônica Maria Ramos do Nascimento França
}

\section{RESUMO}

O presente trabalho, de cunho teórico, analisa principalmente o instituto da Compensação Ambiental como condicionante para o Licenciamento Ambiental. Inicialmente, abordam-se o Licenciamento Ambiental e seu modelo trifásico para concessão de licenças, perpassando pelas Licenças: Prévia, de Instalação e de Operação, citando falhas e características deste processo. Por fim, analisa-se o Instituto da Compensação Ambiental aplicável a empreendimentos de significativo impacto ambiental, englobando o desvio destes recursos para finalidades diversas das estabelecidas. Tal delineamento se mostra necessário, considerando que os institutos que deveriam ser base de uma atividade sustentável nem sempre cumprem esse papel de forma coerente. O estudo de obras jurídicas é adotado como procedimento metodológico.

Palavras-chave: Licenciamento ambiental, Condicionantes, Compensação ambiental

\section{ABSTRACT}

This work, of theoretical nature, mainly analyzes the Institute of Environmental Compensation as a condition for Environmental Licensing. Initially, it discusses environmental licensing and its three-phase model for licensing, passing by Licenses: Preview, installation and operation, citing flaws and characteristics of this process. Finally, it analyzes the Environmental Compensation Institute applicable to significant environmental impact, involving the diversion of these resources for various purposes of these. This design proves necessary, considering that the institutes which should be the basis of a sustainable activity do not always fulfill that role consistently. The study of legal works is adopted as a methodological procedure.

Keywords: Environmental licensing, Restrictions, Environmental compensation

\footnotetext{
${ }^{1}$ Mestranda em Direito Ambiental pela Escola Superior Dom Hélder Câmara -ESDHC, Belo Horizonte, Minas Gerais. Estagiária de Docência na Escola Superior Dom Hélder Câmara -ESDHC, Belo Horizonte, Minas Gerais, (Brasil) Email: tutortreinamento@gmail.com

${ }^{2}$ Mestre em Direito Ambiental e Desenvolvimento Sustentável vela Escola Superior Dom Hélder Câmara -ESDHC. Belo Horizonte, Minas Gerais. Doscente pela Universidade do Estado de Minas Gerais -UEMG, Belo Horizonte, Minas Gerais, (Brasil).
} 


\section{INTRODUÇÃO}

A tecnologia alcançada nos últimos anos, especialmente após a Revolução Industrial, trouxe muitas benesses para a coletividade, na medida em que as necessidades humanas passaram a ser atendidas por um espectro de produtos nunca antes visto. Contudo, a exploração ambiental de forma inconsequente vem causando degradação e comprometendo, inclusive, recursos vitais, à guisa do decantado princípio do desenvolvimento sustentável.

O advento da Constituição de 1988 foi fundamental para que o Brasil se envolvesse, ao menos em tese, de maneira profunda com as questões ambientais, ainda que leis esparsas, recepcionadas pela Carta Magna, já se prestavam a adotar medidas extremamente importantes para a defesa do meio ambiente. Dentre tais medidas, há o instrumento do Licenciamento Ambiental, instituído pela Lei de Política Nacional de Meio Ambiente em 1981, com o intuito de exercer algum controle dos recursos ambientais.

Em que pese tratar-se de instrumento fundamental, o Licenciamento Ambiental nem sempre cumpre efetivamente sua função sistemática de controle, com ações preventivas e corretivas. Tal ineficiência se deve, também, aos diversos fatores técnicos envolvidos na concessão da Licença Ambiental e em decorrência da especificidade de cada etapa. Além disso, o Licenciamento exige capacitação e aparelhamento do corpo técnico dos órgãos fiscalizadores (nem sempre constatados) e o cumprimento das Compensações Ambientais estabelecidas como condicionantes para sua concessão.

Com relação às compensações ambientais em particular, o problema reside no fato de que, em muitos casos, este requisito não cumpre as funções a que foi destinado. Por isso, acaba por se tornar verdadeiro paliativo, principalmente quando envolve políticas públicas, uma vez que as questões ambientais são relegadas a um segundo plano, sob o argumento de ser necessário atender as demandas de saúde, educação, infraestrutura, dentre outras. Ainda que o Poder Público não satisfaça adequadamente tais demandas.

O presente trabalho busca fazer uma breve análise acerca da eficácia das Compensações Ambientais condicionantes dos Licenciamentos Ambientais. Para seu desenvolvimento, foi 
realizado ampla revisão de literatura em revistas jurídicas de circulação nacional, doutrinas, dissertação e teses

\section{1- A COMPENSAÇÃO AMBIENTAL NOS PROCESSOS DE LICENCIAMENTO}

\section{a. Licenciamento Ambiental}

De acordo com a descrição do anexo da Resolução CONAMA 237/97, os empreendimentos causadores de significativos impactos ambientais estão sujeitos ao Licenciamento Ambiental. Este instituto, ainda que muito criticado por adotar meios onerosos e burocráticos que acabam por inviabilizar muitos empreendimentos, continua sendo o pilar da política ambiental no Brasil, por ser, de certa forma, o único instrumento capaz de minimizar os danos. É o procedimento administrativo por meio do qual o poder público autoriza a instalação, ampliação, modificação e operação de atividades ou empreendimentos utilizadores de recursos ambientais considerados efetiva ou potencialmente poluidores.

O inciso I do art. $1^{\circ}$ da Resolução n. 237, de 19 de setembro de 1997, do CONAMA conceitua Licenciamento Ambiental como ato inerente ao Poder Executivo para controle das práticas humanas sobre o ambiente natural:

Art. $1^{\circ}$ - Para efeito desta Resolução são adotadas as seguintes definições:

I - Licenciamento Ambiental: procedimento administrativo pelo qual o órgão ambiental competente licencia a localização, instalação, ampliação e a operação de empreendimentos e atividades utilizadoras de recursos ambientais, consideradas efetiva ou potencialmente poluidoras ou daquelas que, sob qualquer forma, possam causar degradação ambiental, considerando as disposições legais e regulamentares e as normas técnicas aplicáveis ao caso.

Parafraseando Ribeiro (2015), em âmbito nacional, o instituto foi criado pela Lei da Política Nacional de Meio Ambiente (Lei 6938/81) e regulamentado pelo Decreto 88.351/83, substituído pelo Decreto 99.274/90 em conformidade com a CR/88, que instituiu a 
obrigatoriedade do prévio licenciamento para as atividades de significativo impacto ambiental. O Licenciamento Ambiental é considerado ato administrativo vinculado, pelo qual o Poder Público poderá ou não expedir a licença específica em cada caso.

Licenciamento Ambiental pode ser definido como um procedimento administrativo destinado a licenciar atividades ou empreendimentos utilizadores de recursos ambientais, efetiva ou potencialmente poluidores ou capazes, sob qualquer forma, de causar degradação ambiental(THOMÉ, 2014, p. 237).

Para Rogério Pagel (2002), a distinção entre licença e licenciamento ambiental consiste em:

Verifica-se, então, que a licença ambiental difere do licenciamento ambiental, na medida em que este possui caráter preventivo, para fins de evitar ou minimizar os danos ao meio ambiente, e, sobretudo, pelo fato de que é um procedimento administrativo realizado anterior à licença ambiental, cujo objetivo é verificar se sua concessão causará ou não degradação ambiental. Nesse viés, verifica-se que o licenciamento ambiental é pressuposto para a concessão de licença. (PAGEL, 2002, p. 233)

O mesmo autor assim entende a necessidade do licenciamento:

\begin{abstract}
Ante a necessidade de um meio ambiente ecologicamente equilibrado, todas as atividades humanas das quais resultam modificação na seara ambiental e que possam ocasionar algum prejuízo, ou melhor, um dano ambiental presente ou futuro, estão condicionados a procedimentos de concordância do Poder Público. Essa concordância é um instrumento para a garantia da qualidade de vida das presentes e futuras gerações. Com efeito, é um dos mais importantes instrumentos da Política Nacional do Meio Ambiente, sendo obrigatório para atividades potencialmente degradadoras do meio ambiente; é também uma forma de regulamentar a maioria das atividades humanas. Assim, um meio ambiente equilibrado sempre dependerá de ações estatais para restringir ou ampliar as atuações empresariais ou individuais
\end{abstract}

O processo de Licenciamento Ambiental para a concessão de licença geralmente será precedido de Estudos Ambientais assim definidos no art. $1^{\circ}$, incisos III e IV da Resolução 237/97 - CONAMA: 
Art. $1^{\circ}$ - Para efeito desta Resolução são adotadas as seguintes definições:

III - Estudos Ambientais: são todos e quaisquer estudos relativos aos aspectos ambientais relacionados à localização, instalação, operação e ampliação de uma atividade ou empreendimento, apresentado como subsídio para a análise da licença requerida, tais como: relatório ambiental, plano e projeto de controle ambiental, relatório ambiental preliminar, diagnóstico ambiental, plano de manejo, plano de recuperação de área degradada e análise preliminar de risco.

IV - Impacto Ambiental Regional: é todo e qualquer impacto ambiental que afete diretamente (área de influência direta do projeto), no todo ou em parte, o território de dois ou mais Estados.

A já citada norma, no artigo $3^{\circ}$ determina que para empreendimentos considerados de grande impacto ambiental será exigido o Estudo de Impacto Ambiental (EIA) acompanhado pelo Relatório do Impacto Ambiental (RIMA).

Art. $3^{\circ}$ - A licença ambiental para empreendimentos e atividades consideradas efetiva ou potencialmente causadoras de significativa degradação do meio dependerá de prévio estudo de impacto ambiental e respectivo relatório de impacto sobre o meio ambiente (EIA/RIMA), ao qual dar-se-á publicidade, garantida a realização de audiências públicas, quando couber, de acordo com a regulamentação.

O EIA/RIMA deverá ser confeccionado por uma equipe multidisciplinar, considerando o impacto da atividade sobre os diversos meios ambientais: natureza, patrimônio cultural e histórico, o meio ambiente do trabalho e o antrópico. Cumpre o princípio da publicidade, pois permite a participação pública na aprovação de um processo de licenciamento ambiental que contenha este tipo de estudo, através de audiências públicas com a comunidade que será afetada pela instalação do empreendimento licenciado.

O Licenciamento Ambiental poderá ser corretivo e preventivo. O Corretivo é excepcional, devendo apenas ser utilizado nos casos em que a obra já foi instalada e encerrá-la 
acarretaria em prejuízos socioeconômicos de grande monta. Por outro lado, o Licenciamento Preventivo é a regra, apresentando um modelo trifásico: Licença Prévia (LP) e Licença de Instalação (LI), que são preliminares, e a licença definitiva intitulada Licença de Operação (LO). Este modelo foi apresentado pelo Decreto 99.274/90.

A Licença Prévia é a fase intencional, geralmente requerida após os procedimentos do EIA/RIMA, norteadores do órgão ambiental na definição das condições que possibilitarão a concessão ou não da licença para realização do empreendimento. Considerada um instrumento de negociação e adaptação, a Licença Prévia, exatamente por sua natureza, é um mecanismo dinâmico, pois permite mudanças nos planos da atividade, bem como a realização de audiências públicas e todos os meios para alcançar o equilíbrio ambiental, econômico e social. Em Minas Gerais, a Secretaria de Estado de Meio Ambiente e Desenvolvimento Sustentável, SEMAD, assim conceitua:

Licença Prévia (LP): é concedida na fase preliminar de planejamento do empreendimento ou atividade aprovando, mediante fiscalização prévia obrigatória ao local, a localização e a concepção do empreendimento, bem como atestando a viabilidade ambiental e estabelecendo os requisitos básicos e condicionantes a serem atendidas nas próximas fases de sua implementação. Tem validade de até quatro anos. (disponível em: $\quad \underline{\text { htp://www.meioambiente.mg.gov.br/regularizacao- }}$ ambiental/licenciamento, aces so 09 de agosto de 2015)

A Licença de Instalação, por sua vez, autoriza a instituição da atividade de acordo com os planos. A SEMAD entende que a:

Licença de Instalação (LI): autoriza a instalação do empreendimento ou atividade de acordo com as especificações constantes dos planos, programas e projetos aprovados, incluindo as medidas de controle ambiental e demais condicionantes. Tem validade de até seis anos. (disponível em: http://www.meioambiente.mg.gov.br/regularizacao-ambiental/licenciamento, acesso 09 de agosto de 2015) 
Também nessa fase, o projeto original poderá ser reestruturado, com a elaboração do Projeto Executivo, mais pormenorizado. Acerca do Projeto Executivo, Talden Farias (2011) explica:

\begin{abstract}
Após a aprovação do Projeto Executivo, é expedida a licença de instalação contendo as especificações de natureza legal e técnica para a efetiva proteção do meio ambiente, sendo somente a partir daí que o órgão ambiental autoriza a implantação da atividade. (FARIAS, 2011, p. 74)
\end{abstract}

Por fim, a Licença de Operação está condicionada ao cumprimento das fases anteriores à fiscalização para, segundo Ribeiro (2015), verificar se as medidas mitigadoras - os projetos de controle - e as medidas compensatórias foram implantadas conforme aprovadas nas fases anteriores, identificando, ainda, se o empreendimento respeitou a legislação ambiental, os estudos EIA/RIMA e qualquer outra condicionante imposta nas fases anteriores. O já citado órgão mineiro entende como:

Licença de Operação (LO): autoriza a operação da atividade ou empreendimento, após fiscalização prévia obrigatória para verificação do efetivo cumprimento do que consta das licenças anteriores, tal como as medidas de controle ambiental e as condicionantes porventura determinadas para a operação. É concedida com prazos de validade de quatro ou de seis anos estando, portanto, sujeita à revalidação periódica. A LO é passívelde cancelamento, desde que configurada a situação prevista na norma legal. (disponível em: http://www.meioambiente.mg.gov.br/regularizacaoambiental/licenciamento, acesso 09 de agosto de 2015)

Em tese, as licenças sujeitam-se ao cumprimento de todas essas etapas. Contudo, na prática, a falta de estrutura, a ausência de técnica e conhecimento, bem como excessivas condicionantes acarretam em inoperância dos órgãos ambientais, causando transtorno aos empreendimentos e entraves de investimentos

De acordo com notícia publicada pelo jornal $O$ Tempo $^{l}$ em junho de 2015, existem, hoje, 2.800 projetos parados na Secretaria de Meio Ambiente do Estado de Minas Gerais na fila do licenciamento. Desse total, 94 já têm até protocolos de intenção assinados e somam 
investimentos de $\mathrm{R} \$ 40$ bilhões, que, se tivessem saído do papel, poderiam gerar 25 mil empregos diretos.

Nos termos da Lei 9985 de 2.000, que instituiu o Sistema Nacional de Unidades de Conservação da Natureza o empreendedor de empreendimentos de significativo impacto ambiental, é obrigado a apoiar a implementação e manutenção de unidade de conservação do Grupo de Proteção Integral. Segundo investigações do Ministério Público de Minas Gerais (MPMG), que acarretou em Recomendação no ano de 2013, existem 73 unidades de conservação estaduais de proteção integral em Minas Gerais, mas 426.392,44 hectares, do total de áreas protegidas (605.921,67 hectares), não foram ainda desapropriados pelo Estado, de forma que $70.38 \%$ das unidades de conservação mineiras existem apenas no papel.

A maioria das cobranças que deveriam partir do órgão ambiental competente (e que não o são por inoperância) acaba sendo objetos posteriores de Termos de Ajustamento de Condutas - TAC's, firmados pelo Ministério Público. Acerca de investigações do MPMG, que datam do ano de 2013, existem mais de 69 milhões de reais pendentes de pagamento por empreendimentos só em Minas Gerais. E ainda, naquele ano, existiam 531 processos de compensação ambiental envolvendo grandes empreendimentos, sendo que os mais antigos, com trâmite iniciado em 2004, estão aguardando "emissão de ofício solicitando informações para instrução". Para o MPMG, existe flagrante leniência da Secretaria Estadual de Meio Ambiente e Desenvolvimento Sustentável no trato da instrução dos processos de compensação ambiental e arrecadação dos valores apurados, o que priva o erário ambiental do recolhimento de centenas de milhões de reais que deveriam ser destinados à implantação e gestão das unidades de conservação existentes no território mineiro, mormente para a sua regularização fundiária ${ }^{2}$.

1 Reportagem Burocracia trava investimento de R\$ 40 bilhões em Minas, publicada pelo portal online do jornal $O$ Tempo em 17/06/15. Disponível em: http://www.otempo.com.br/capa/economia/burocracia-travainvestimento-de-r-40-bilh\%C3\% B5es-em-minas-1.1056026

\footnotetext{
${ }^{2}$ Matéria MPMG recomenda à Semad que cobre medidas compensatórias ambientais de empreendedores inadimplentes, publicada em 04/11/2013 no portal oficial do MPMG. Disponível em: http://www.mpmg.mp.br/comunicacao/noticias/mp mg-reco menda-a-semad-que-cobre-medidas-compens atoriasambientais-de-empreendedores-inadimplentes.html
} 
Para que a efetividade do Licenciamento Ambiental fosse alcançada, seria necessária, a princípio, a desburocratização, pois a imposição de diversas condicionantes, a falta de equipamento e, principalmente, a ausência de pessoal preparado nos órgãos ambientais acabam por inviabilizar a eficácia das fiscalizações. Ademais, as licenças não devem ser utilizadas como moeda de troca, que buscam nas compensações ambientais uma forma de implementar as garantias sociais esperadas do Poder Público.

\section{b. A Compensação Ambiental como condicionante de licenças ambientais}

A compensação ambiental do SNUC somente incidirá sobre atividade geradora de significativo impacto ambiental, que deverá ser apurado através de Estudo de Impacto Ambiental e respectivo relatório - EIA/RIMA. Conclui-se, pois, que o EIA/RIMA é instrumento essencial para a apuração dos impactos ambientais significativos. Como forma de nortear a atuação dos órgãos ambientais, o CONAMA, por meio da Resolução $n^{\circ}$ 01/86, elencou atividades para as quais seria obrigatoriamente exigido o EIA/RIMA.

A compensação ambiental engloba todas as medidas de substituição de um bem danificado por outro de valor equivalente, tem por escopo "aliviar" as consequências de um prejuízo causado ao meio ambiente, com um benefício ambiental que possa ter um significado muito próximo ao bem prejudicado. Está, via de regra, associada a um dano.

Instituída pela Resolução Conama 10/87 (exigida dos empreendimentos que pudessem destruir florestas e outros ecossistemas, em favor da implantação de uma Estação Ecológica), substituída pela Resolução Conama 2/96 (ampliou o objeto da compensação ambiental, permitindo que os recursos desembolsados pelo empreendedor a esse título fossem aplicados em outras unidades de conservação públicas de proteção integral (uso indireto) que não as estações ecológicas). Atualmente disciplinada também pelo art. 36 da Lei 9.985/00, arts. 31 a 34 do Decreto 4.340/02 (alterados pelo Decreto 6.848/09) e Resolução Conama 371/06. 
Conforme já expresso anteriormente, p art. 36 da Lei 9.985/00 estabeleceu que, nos casos de licenciamento ambiental de empreendimentos de significativo impacto ambiental, avaliados pelo órgão ambiental competente, o empreendedor será obrigado a apoiar implantação e manutenção de unidade de conservação como forma de compensar o meio ambiente pelos danos sofridos, vejamos:

\begin{abstract}
Art. 36. Nos casos de licenciamento ambiental de empreendimentos de significativo impacto ambiental, assim considerado pelo órgão ambiental competente, com fundamento em estudo de impacto ambiental e respectivo relatório - EIA/RIMA, o empreendedor é obrigado a apoiar a implantação e manutenção de unidade de conservação do Grupo de Proteção Integral, de acordo como disposto neste artigo e no regulamento desta Lei.
\end{abstract}

$\S 1$ o O montante de recursos a ser destinado pelo empreendedor para esta finalidade não pode ser inferior a meio por cento dos custos totais previstos para a implantação do empreendimento, sendo o percentual fixado pelo órgão ambiental licenciador, de acordo com o grau de impacto ambiental causado pelo empreendimento.

$\S 2$ ㅇ Ao órgão ambiental licenciador compete definir as unidades de conservação a serem beneficiadas, considerando as propostas apresentadas no EIA/RIMA e ouvido o empreendedor, podendo inclusive ser contemplada a criação de novas unidades de conservação.

§ 3o Quando o empreendimento afetar unidade de conservação específica ou sua zona de amortecimento, o licenciamento a que se refere o caput deste artigo só poderá ser concedido mediante autorização do órgão responsável por sua administração, e a unidade afetada, mesmo que não pertencente ao Grupo de Proteção Integral, deverá ser uma das beneficiárias da compensação definida neste artigo.

Conforme explica Siqueira (2014) a compensação ambiental está totalmente relacionada com o licenciamento ambiental, vejamos:

\begin{abstract}
A compensação ambiental prevista na Lei no 9.985/00 - ou "compensação ambiental do SNUC", assim denominada na prática jurídico ambiental - , está diretamente relacionada ao licenciamento ambiental. Trata-se, com efeito, de mecanismo de compens ação de impactos ambientais causados por atividade empreendedora através da arrecadação de recursos que viabilizarão, em última análise, o SNUC, mais especialmente o grupo de unidades de conservação de proteção integral. (p. 207)
\end{abstract}

As Compensações Ambientais devem ser analisadas no momento preliminar da licença, ou seja, durante a Licença Prévia, para que efetivamente cumpram sua função de 
minimizar o dano, ao invés de serem utilizadas como moeda de troca entre os órgãos ambientais e os empreendedores

Portanto, o que vem ocorrendo costumeiramente é que os grandes empreendimentos têm se tornado referência de implementação de políticas públicas e direitos sociais, fazendo as vezes do Estado, que descumpre sua função. Desta feita, em muitos casos, os impactos ambientais deixam de ser reduzidos e são substituídos por ações que deveriam partir do Poder Público.

Ribeiro (2015) completa que, além da complementação de estudos e levantamentos, observa-se, também, a prática de incluir nas condicionantes, como, por exemplo, doações de equipamentos, obras de infraestrutura, entre outras, o que desmoraliza o licenciamento e o transforma em balcão de negócios, com os já conhecidos resultados: morosidade, elevação de custos, chantagens, judicialização com ações civis públicas, etc. (p.20)

De acordo com o Centro de Apoio Operacional das Promotorias de Justiça de Defesa do Meio Ambiente, segundo matéria divulgada em abril de $2013^{3}$, como o Estado de Minas Gerais e o Instituto Estadual de Florestas (IEF) vêm descumprindo o que determina a Lei Federal 9.985/2000 (Lei do Sistema Nacional de Unidades de Conservação), o Ministério Público de Minas Gerais ajuizou Ação Civil Pública (ACP) para exigir que os mais de 198 milhões de reais já arrecadados para fins de compensação ambiental sejam destinados à implantação e manutenção das Unidades de Conservação, considerando que o Inquérito Civil constatou o contingenciamento dos recursos para uso em outras finalidades, em detrimento do meio ambiente.

Importante sempre frisar que o Instituto da Compensação Ambiental não tem natureza de penalidade. Na verdade, o ato de compensação é uma recompensa à coletividade pelo uso do bem comum, reforçado pelo princípio do poluidor-pagador. Independentemente de o empreendimento desempenhar o que the foi imposto pela compensação ambiental, eventual dano causado além do previsto deverá ser reparado nas esferas cível, criminal e administrativa.

O que se espera é que os recursos provenientes das Compensações Ambientais se prestem a recuperar ou reduzir o impacto ambiental que os empreendimentos porventura vierem

${ }^{3}$ Matéria Ação do MPMG requer a aplicação efetiva de cerca de 200 milhões na implantação de unidades de conservação, publicada em 30/04/2013 no portal oficial do MPMG. Disponível em: http://www.mpmg.mp.br/comunicacao/noticias/acao-do-mpmg-requer-a-aplicacao-efetiva-de-cerca-de-r-200milhoes-na-implantacao-e-manutencao-de-unidades-de-conservacao.htm\#.VZ7xZ ke0ZM 
a causar, sempre que possível, dentro do mesmo bioma e favorecendo ambientalmente a comunidade diretamente atingida.

\section{CONSIDERAÇÕES FINAIS}

A atual Constituição oferece os pilares para a tutela efetiva do meio ambiente, considerando que qualquer atividade humana, especialmente os grandes empreendimentos, gera impactos socioambientais. O Licenciamento Ambiental, dada sua natureza, deveria ser capaz de delimitar tais impactos, reduzir os danos e alcançar minimamente o equilibrio entre atividades econômicas e o meio ambiente, conforme preconiza o princípio do desenvolvimento sustentável.

Para que a efetividade do Licenciamento Ambiental seja alcançada, é necessária, a princípio, a desburocratização, pois a imposição de diversas condicionantes, a falta de equipamento e, principalmente, a ausência de pessoal preparado nos órgãos ambientais acabam por inviabilizar a eficácia das fiscalizações. Ademais, as licenças não devem ser utilizadas como moeda de troca, que buscam nas compensações ambientais uma forma de implementar as garantias sociais esperadas do Poder Público.

Conforme demonstrado ao longo do trabalho, a compensação ambiental é um instrumento de política pública que, intervindo junto aos agentes econômicos, proporciona a incorporação dos custos sociais e ambientais da degradação gerada por determinados empreendimentos, podendo ser entendida como um mecanismo de responsabilização dos empreendedores causadores de significativo impacto ambiental pelo prejuízo que causam ao meio ambiente.

Como a atividade econômica por eles desenvolvida repercute negativamente sobre um bem de uso comum do povo, o meio ambiente, deve o empreendedor, em contrapartida a sua atividade danosa, apoiar mecanismos que promovam a preservação ambiental. Por essa razão a lei prevê o investimento na criação, manutenção e implantação de unidades de conservação, que, sabidamente, são essenciais na preservação dos diferentes ecossistemas e fundamentais para a manutenção do equilíbrio biológico. 
Há que se considerar que os recursos provenientes devem ser investidos na recuperação ou redução dos impactos ambientais, sempre que possível, dentro do mesmo bioma e favorecendo ambientalmente a comunidade diretamente atingida.

A junção de legislação adequada e devidamente aplicada à fiscalização eficiente, ao planejamento socioambiental e à efetiva participação da comunidade diretamente interessada, nos termos do princípio da participação popular, possibilitará efetiva proteção ambiental, atendendo às expectativas mais prósperas.

\section{REFERÊNCIAS}

BRASIL. Constituição (1988). Constituição da República Federativa do Brasil. Brasîlia: Senado Federal, Centro Gráfico, 1988.

BRASIL. Decreto 99.274, de 06 de junho de 1990. Dispõe sobre a criação de Estações Ecológicas e Áreas de Proteção Ambiental e sobre a Política Nacional do Meio Ambiente, e dá outras providências. Diário Oficial, Brasilia, 06 de junho de 1990.

BRASIL. Decreto 4340/02, de 22 de agosto de 2002. Regulamenta artigos da Lei $n^{\circ}$ 9.985, de 18 de julho de 2000, que dispõe sobre o Sistema Nacional de Unidades de Conservação da Natureza - SNUC, e dá outras providências. Diário Oficial, Brasîlia, 22 de agosto de 2002.

BRASIL. Decreto Lei 6230/44. DC, de 29 de janeiro de 1944. Disponível em: http://www2.camara.leg.br/legin/fed/declei/1940-1949/decreto- lei-6230-29-janeiro-1944416317-publicacaooriginal-1-pe.html.Acesso em: 03 jun. 2014

BRASIL. Dos Ministérios. Lei 10683/2003, de 28 de maio de 2003. Disponível em: http://www.planalto.gov.br/ccivil_03/leis/2003/110.683.htm.Acesso em: 03 jun. 2014

BRASIL. Lei 9985, de 18 de julho de 2000. Regulamenta o art. 225, § 1ํㅡ, incisos I, II, III e VII da Constituição Federal, institui o Sistema Nacional de Unidades de Conservação da Natureza e dá outras providências.Diário Oficial, Brasilia, 18 de julho de 2000. 
BRASIL. Lei 6938, de 31 de agosto de 1981. Dispõe sobre a Política Nacional do Meio Ambiente, seus fins e mecanismos de formulação e aplicação, e dá outras providências.Diário Oficial, Brasília, 31 de agosto de 1981.

BRASIL. Lei 9985, de 18 de julho de 2000.Regulamenta o art. 225, $\S 1^{\circ}$, incisos I, II, III e VII da Constituição Federal, institui o Sistema Nacional de Unidades de Conservação da Natureza e dá outras providências.Diário Oficial, Brasîlia, 18 de julho de 2000.

BRASIL. Resolução 237, de 19 de janeiro de 1997.Disciplina O CONSELHO NACIONAL DO MEIO AMBIENTE - CONAMA, no uso das atribuições e competências que the são conferidas pela Lei $\mathrm{n}^{\circ}$ 6.938, de 31 de agosto de 1981, regulamentadas pelo Decreto $\mathrm{n}^{\circ}$ 99.274, de 06 de junho de 1990, e tendo em vista o disposto em seu Regimento Interno.Diário Oficial, Brasilia, 19 de janeiro de 1997.

COSTA, Beatriz Souza. A Cidade: O Contexto Urbano e os Impactos Ambientais. In: RIOS, Mariza; CARVALHO, Newton Teixeira; KLEINRATH, Stella de Moura. A Cidade Real e a Cidade Ideal em uma reflexão transdisciplinar. Editora: Del Rey, Belo Horizonte, 2014. P.49-68.

. Meio Ambiente como Direito a Vida - Brasil - Portugal - Espanha. Belo Horizonte: Editora Lutador, 2010.

ENRÍQUEZ, Maria Amélia. Mineração: Maldição ou Dádiva? São Paulo: Signus, 2008. FARIAS, Talden. Licenciamento Ambiental: aspectos teóricos e práticos. $3^{\text {a }}$ ed. Belo Horizonte: Fórum, 2011.

FEIGELSON, Bruno. Curso de Direito Minerário. São Paulo: Editora Saraiva, 2014, $2^{\mathrm{a}}$ ed., p. 102

FIORILlO, Celso Antonio Pacheco. Princípios do Direito Processual Ambiental. 5.ed. São Paulo: Saraiva, 2012.

FIORILlO, Celso Antonio Pacheco. Princípios do Direito Processual Ambiental. 5.ed. São Paulo: Saraiva, 2012. 
MACHADO, Paulo Affonso Leme. Direito Ambiental Brasileiro. 23.ed., São Paulo: Malheiros, 2015.

MILARÉ, Édis. Direito do Ambiente. 8a ed. São Paulo: Revista dos Tribunais, 2013.

PAGEL, Rogério. A Responsabilidade Civil do Estado Frente à Concessão de Licença Ambiental. Revista Veredas do Direito: Direito Ambiental e Desenvolvimento Sustentável, volume $9, \mathrm{n}^{\circ}$ 18, julho de 2012. p.229/248.

RIBEIRO, José Cláudio Junqueira. O que é Licenciamento Ambiental. In: RIBEIRO, José Cláudio Junqueira (Org.). Licenciamento Ambiental: herói, vilão ou vítima? Belo Horizonte: Arraes, 2015.p. 1/26

SAMPAIO, José Adércio Leite. A Constitucionalização dos Princípios de Direito Ambiental. In: SAMPAIO, José Adércio Leite, WOLD, Chris, NARDY, Afrânio: Princípios de Direito Ambiental: na Dimensão Intemacional e Comparada. Belo Horizonte: Del Rey, 2007

SIQUEIRA, Lyssandro Norton. Os princípios de Direito Ambiental e a compensação ambiental no Sistema Nacional de Unidades de Conservação (SNUC). In: GOMES, Carla Amado: Compensação ecológica, serviços ambientais e protecção da biodiversidade. Lisboa. Instituto de Ciências Jurídico-Políticas, 2014.

SIRVINSKAS, Luís Paulo. Manual de direito Ambiental. 11 ed. Rev. Atual. E e ampl. São Paulo: Saraiva, 2013.

SILVA, José Afonso da. Direito Ambiental Constitucional. $5^{\mathbf{a}}$ ed. São Paulo: Malheiros Editores, 2004.

TEIXEIRA, Orci Paulino Bretanha. O direito ao meio ambiente ecologicamente equilibrado como direito fundamental. Porto Alegre: Livraria do Advogado, 2006.

THOMÉ, Romeu Faria. A Compensação Ambiental, Disponível em: http://www.domtotal.com/colunas/detalhes.php?artId=2650. Acesso em 13 de agosto de 2015. THOMÉ, Romeu. Manual de Direito Ambiental. 4a edição. Salvador: Juspodivm, 2014. 
THOMÉ, Romeu. O Princípio da vedação de retrocesso socioambiental no contexto da sociedade de risco. Salvador: Juspodivm, 2014.

TRENNEPOHL, Curt; TRENNEPOHL, Terence. Licenciamento Ambiental. $3^{\text {a }}$ ed. Niterói: Impetus, 2010. 